\title{
Physical Exercise Does Not Improve Colon Inflammation in Mice Induced Lambda Carrageenan
}

\author{
Ana Qonitatillah ${ }^{1^{*}}$, Kristanti Wanito Wigati ${ }^{2}$, Roedi Irawan ${ }^{3}$ \\ ${ }^{1}$ Medical Science Program, ${ }^{2}$ Physiology Department, ${ }^{3}$ Child Health Department, Nutrition and Metabolic \\ Disease Division. Dr. Soetomo General Hospital, \\ Faculty of Medicine, Universitas Airlangga, \\ UNAIR A-Campus, Tambaksari, Surabaya, East Java, Indonesia 60132 \\ *Corresponding author: anaqonitatillah2@gmail.com
}

\begin{abstract}
Inflammatory Bowel Disease (IBD) is a well known reported gastrointestinal tract disease, which the prevalence continous to increase in Southeast Asia and other developing countries. Animal model have already been widely used for gut inflammation study. Lambda $(\lambda)$ carrageenan is a chemical substance which commonly used to induced inflammation in IBD animal models. Physical exercise is a non-pharmacological therapy recommended for IBD. However, further study is needed to determine the effects of this therapy. This study was aimed to determine the physical exercise effect on colon inflammation in mice induced $\lambda$-carrageenan. Thirtyeight mice were divided into 2 groups. Control group (C) which induced with $\lambda$-carrageenan and treatment group $(\mathrm{T})$ which induced by $\lambda$-carrageenan and treadmill exercise. The degree of colon inflammation was obtained by histopathological examination using Hematoxylin-Eosin (HE) staining and inflammation scoring system, which include inflammatory cell infiltration and intestinal architecture. All mice colon samples in both group were inflamed with varying degrees. The treatment group had a higher Inflammatory degree score than control group ( $\mathrm{p}<0.05$ ). Physical exercise does not improved the degree of colon inflammation in mice induced $\lambda$-carrageenan due to uncontrolled stress induction and water intake containing $\lambda$-carrageenan.
\end{abstract}

Key words: IBD, inflammatory cell infiltration, intestinal architecture, $\lambda$-carrageenan, physical exercise, treadmill

Received: 29 November 2019

Revised: 9 Desember 2019

Accepted: 4 Januari 2020

\section{INTRODUCTION}

Inflammatory Bowel Disease (IBD) is intestinal inflammation whose causative factors of the disease are not fully understood yet. Among all gastroenterology cases, IBD, which consist of Ulcerative Colitis (UC) and Crohn's Disease (CD) is widely reported (Whittlem et al., 2010). IBD is associated with immune complex disorders, influenced by genetic and environmental factors (Wehkamp et al., 2016). Physical exercise is constantly associated with an increase in the immune system (Gleeson, 2007). Therefore, IBD patients are encouraged to do physical exercise as a management for the treatment of the disease. Physical exercise recommendations are mainly to reduce symptoms, complications, and extraintestinal manifestations of IBD (Narula and Fedorek, 2008; Packer et al., 2010).
In the last few decades, there have been many experimental studies for examining intestinal inflammation, which is very useful for obtaining new information about the pathogenesis of a disease and preclinical evaluation for a new therapy (Kolios, 2016). Experiments with colitis require induction of chemicals, one of which is $\lambda$-carrageenan, because it has potential inflammatory effect in the bowel. Intestinal tissue that has been induced by chemicals such $\lambda$-carrageenan, has special characteristics when evaluated through histopathological analysis HE staining using a preexisting scoring system (Ghia et al., 2006).

However, the literature which stated that physical exercise can reduce the symptoms of IBD is weak and inconsistent (Narula and Fedorek, 2008). The effectiveness of physical exercise and its mechanism on disease activity is unclear (Narula and Fedorek, 2008). So that further research is needed to strengthen the 
opinion that physical exercise can be done for IBD (Narula and Fedorek, 2008) and experimental and clinical research is also needed to confirm its effectiveness as an inflammatory bowel therapy (Ko and Anyeung, 2014).

This study was aimed to determine the physical exercise effect on colon inflammation in mice (Mus musculus) induced $\lambda$-carrageenan.

\section{MATERIALS AND METHODS}

\section{Ethical Approval}

All procedures were approved ethically under supervision of the Health Research Ethic Comittee, Universitas Airlangga. Letter number 232/EC/KPEK/FKUA/2019.

\section{Animals}

A total of $38 \mathrm{BALB} / \mathrm{c}$ mice were obtained from Animal Laboratory, Biochemistry Departement in Faculty of Medicine, Universitas Airlangga. During the experiment, all mice were housed in a well-controlled environment and kept free access to mineral water and the same animal diet. After a one-week adaptation period, assigned to control and and treatment groups. Both of group were induced by $\lambda$-carrageenan supplemented in drinking water at a concentration of $20 \mathrm{mg} / \mathrm{L}$ (Shang et al., 2017).

The treatment group was given treadmill exercise, $7 \mathrm{~m} /$ minutes for 30 minutes (include 5 minutes warming up, 20 minutes exercise, and 5 minutes cooling down) (Kim et al., 2018), and 3 times a week (Durigan et al., 2009). After six weeks of treatment (Shang et al., 2017), all mice were sacrified with cervical disclocation technique.

\section{Chemical and Reagents} ltd. ${ }^{\circledR}$

$\lambda$-carrageenan, Tokyo Chemical Industry co.,

\section{Sample Collection and Procedure}

Colon samples were collected in the 6th week of the study. Colon samples were fixed in $10 \%$ neutral-buffered formalin for 12-24 hours and embedded in paraffin, cutted and stained with HE. Tissue samples were well-oriented with longitudinally cut crypts to precisely assess alterations in the overall intestinal tissue architecture.

\section{Histopathological Evaluation}

Samples were evaluated by standard light microscope with 100x and 400x magnification. The degree of inflammation was scored based on the criteria for chemically-induced colonic inflammationin the journal by Erben et al., 2014., which shown on Table 1.

\section{Statistical Analysis}

Data were collected and analyzed statistically for correlation between groups using statistical software (IBM SPSS Statistics version 20). All results were considered statistically significant at $p<0.05$.

\section{RESULTS AND DISCUSSIONS}

All of colon samples in both group showed inflammation (38/38) with varying degrees. The number of samples in each score are shown in Figure 1.

In the control group, there was one sample with score 2, twelve samples with score 3, and six samples with score 4 . Score 3 is the dominant score in the control group (Figure 2). In the treatment group, there was one sample with score 3 , seventeen samples with score 4 , and one sample with score 5 . Score 4 is the dominant score in the treatment group (Figure 3). The highest inflammation degree score in this study was 5 (Figure 4). The Inflammation degree score showed significant differences regarding control and treatment group $(p<0.05)$.

Mechanism of Induction $\lambda$-carrageenan to gut inflammation is unclear and multifactorial, partly because of the stimulation of proinflammatory cytokines, damaging the epithelial barrier, and disrupting the innate intestinal mucosal immune response to microorganisms (Malik et al., 2009; Buffie et al., 2009), reducing the amount of glycoprotein in the colon (AlSuhail et al., 1984), inhibiting interaction between macrophages and lymphocytes (Chong 
Table 1. Inflammation scoring system: Inflammation score is the sum of score A and score B

\begin{tabular}{llc}
\hline \multicolumn{2}{c}{ Inflammatory cell infiltrate } & \multirow{2}{*}{ Score A } \\
\hline Severity & Extent & 1 \\
Mild & Mucosa & 2 \\
Moderate & Mucosa and Submucosa & 3 \\
Marked & Transmural & \\
\hline
\end{tabular}

\begin{tabular}{llc}
\hline \multicolumn{1}{c}{ Intestinal Architecture } & & \multirow{2}{*}{ Score B } \\
\hline Epithelial changes & Mucosal Architecture & \\
\hline Focal Erosion & & 1 \\
Erosion & +- Focal Ulceration & 2 \\
& Extended focal ulceration & 3 \\
& +- granulation tissue & \\
& +- pseudopolyps & \\
\hline
\end{tabular}

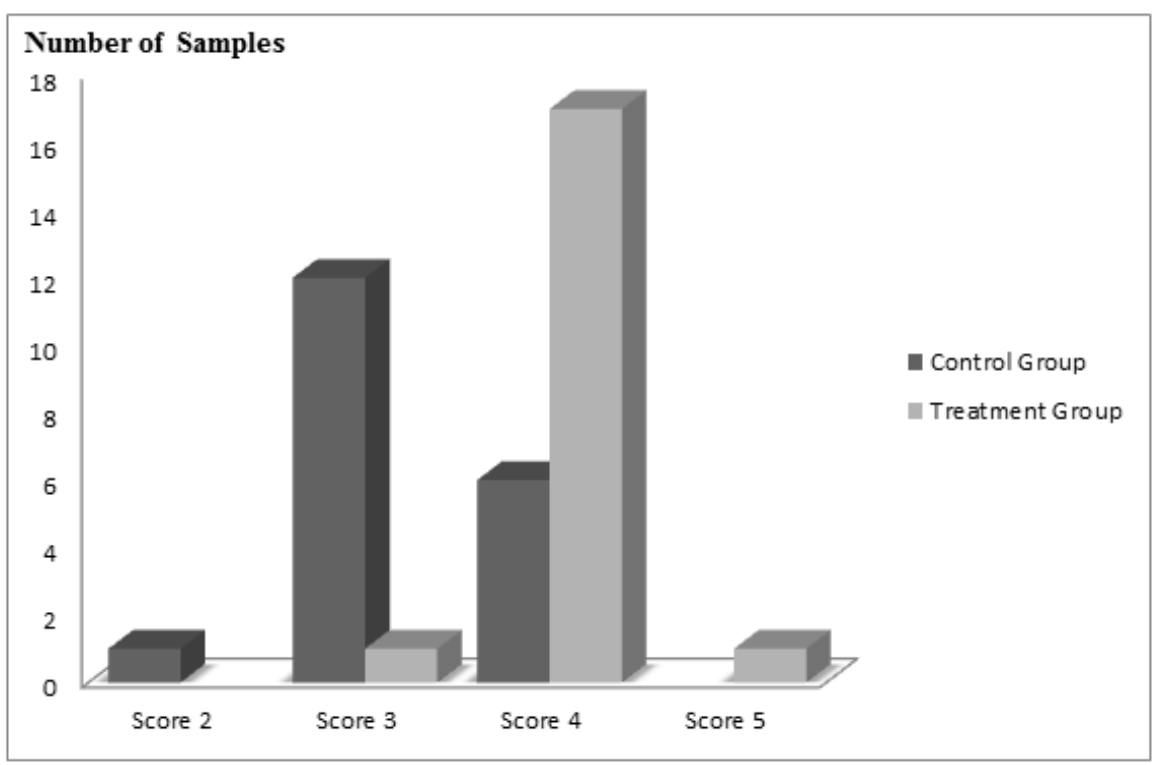

Figure 1. The distribution of the number of samples for each inflammation score

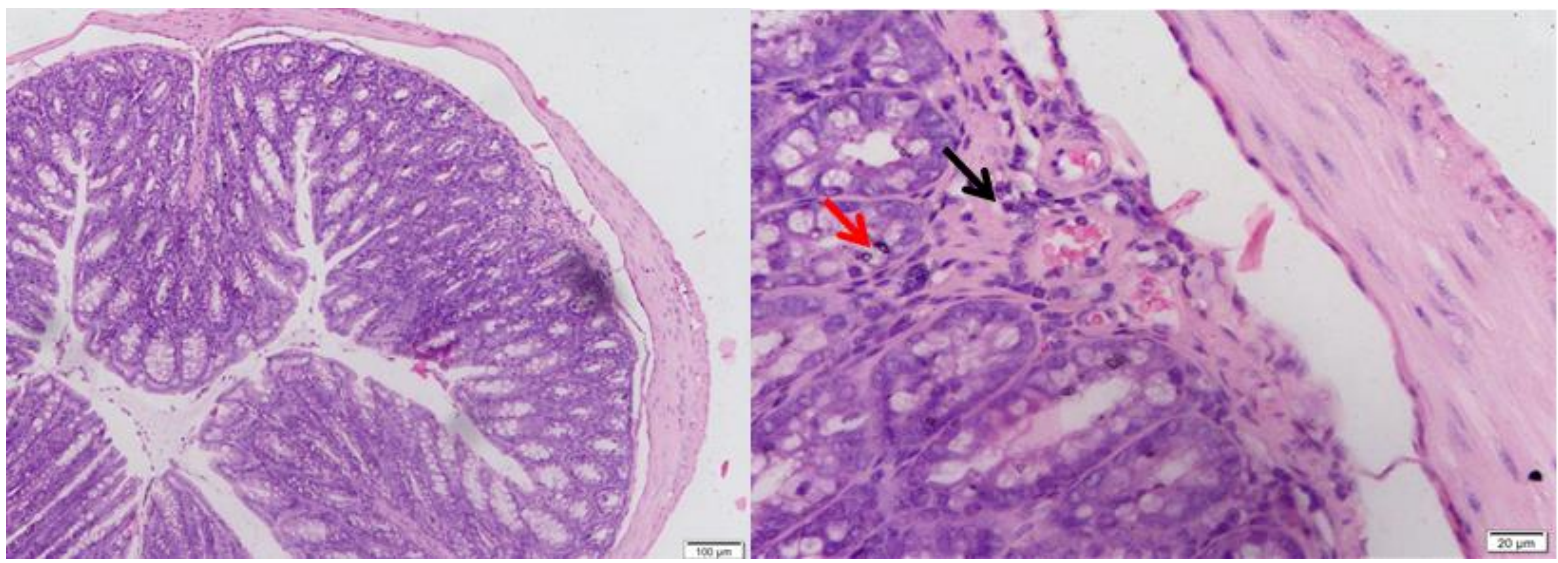

Figure 2. Representating histomorphology of colon tissue with sum scores 3 referred to Table 1, submucosal infiltrates (score A:2) with focal erosion (score B:1); Original magnification $\mathrm{x} 100$ and $\times 400$; black arrows-inflammatory cell infiltration within submucosa; red arrowsfocal erosion; HE tissue stained 


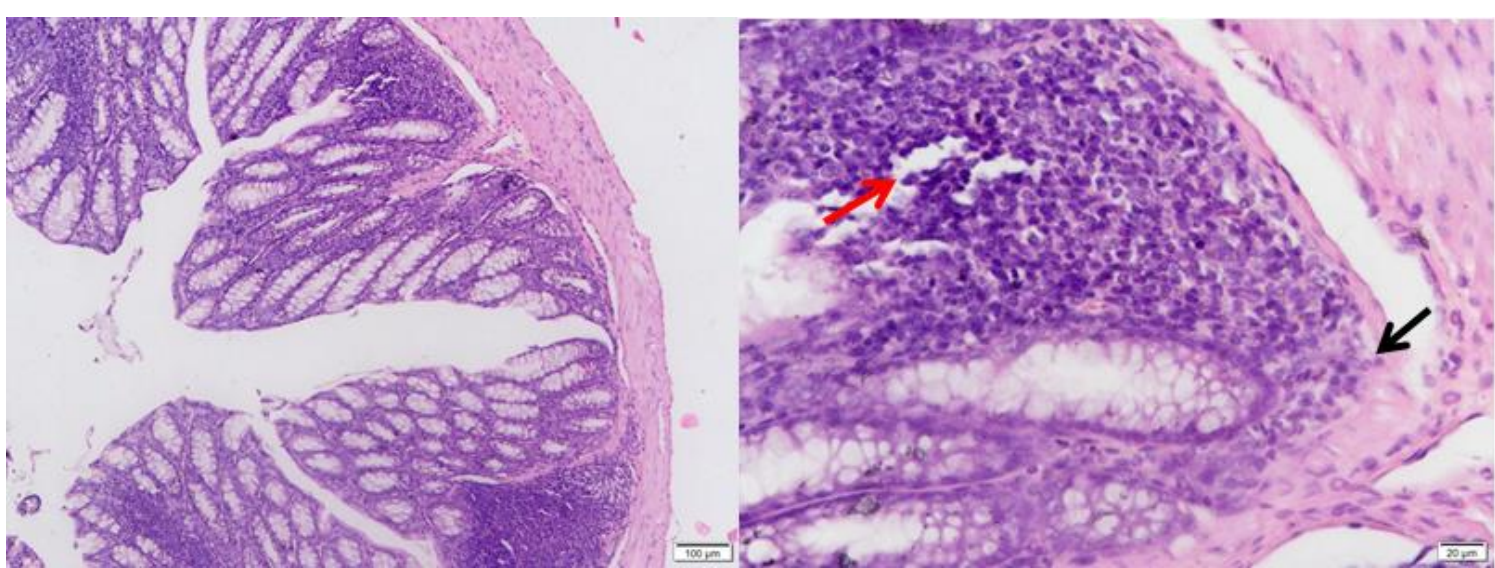

Figure 3. Representating histomorphology of colon tissue with sum scores 4 referred to Table 1 . submucosal infiltrates (score A:2) with focal ulceration (score B:2); Original magnification x100 and $\times 400$; black arrows-inflammatory cell infiltration within submucosa; red arrowsfocal ulceration; HE tissue stained
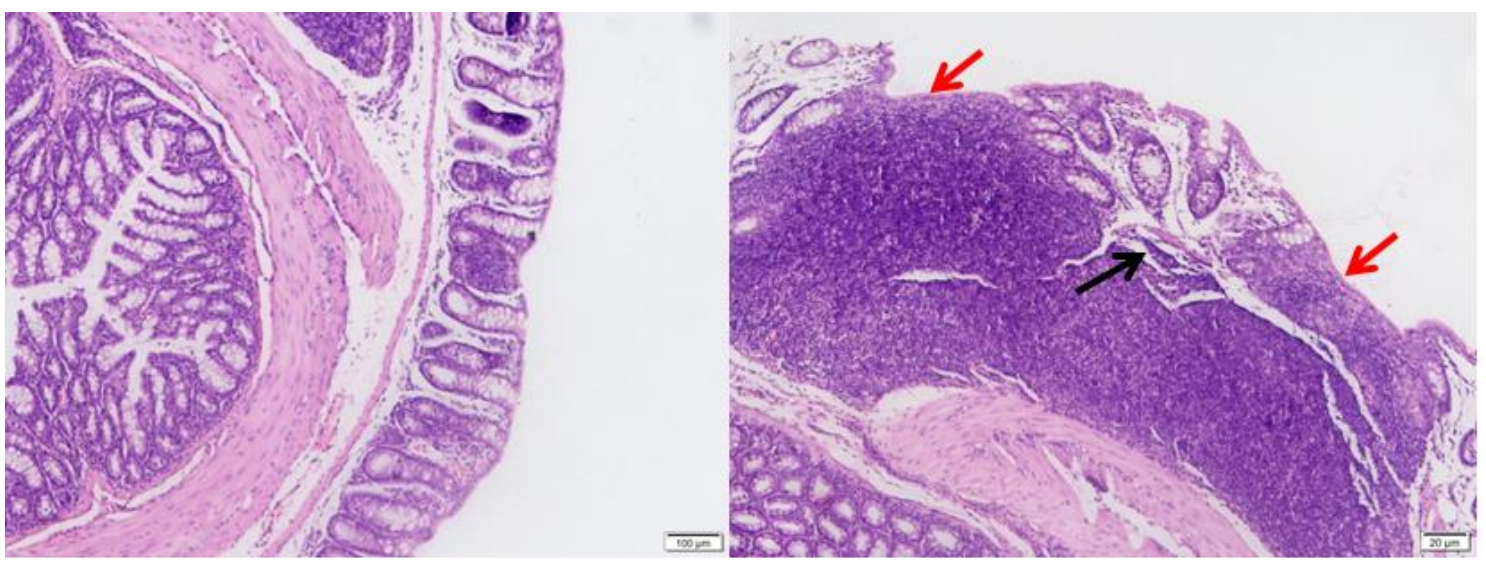

Figure 4. Representating histomorphology of colon tissue with sum scores 5 referred to Table 1. submucosal infiltrates (score A:2) with extensive ulceration (score B:3); Original magnification $\times 100$ and $\times 400$; black arrows-inflammatory cell infiltration within submucosa; red arrows-extensive ulceration; HE tissue stained

and Parish, 1985), induces inflammation in the presence of microbiota because studies in guinea pigs induction carrageenan produces caecum ulceration on days 21-30 (Onderdonk et al., 1977), whereas germ-free guinea pigs do not produce any intestine lesions for up to 6 months of induction (Onderdonk et al., 1978), stimulates the inflammatory cascade in the colon epithelial cell by increasing IL-8 production (Borthakur et al., 2007) which is a key pro-inflammatory cytokines (Martino et al., 2017) and so on. Although the mechanism has not been ascertained, the findings of the effect of carrageenan on intestinal inflammation can already be proven. Increasing IL- 6 and TNF- $\alpha$ expression and reduced IL-10 (Wei et al., 2016) and intestinal inflammation (Wu et al., 2016).

The effect of physical exercise on inflammation has been proven from previous studies, namely reducing the production of inflammatory cytokines in vitro (Flynn et al., 2003), as another example of physical exercise reducing TNF- $\alpha$, IL- 6 , and IL- $1 \beta$ from skeletal muscle in adults (Gielen et al., 2003). However, this study found that physical exercise did not reduce inflammation. There are several studies that have found that physical exercise does not alleviate inflammation, especially not significantly reducing inflammatory biomarkers (Nicklas et al., 2004; Marcell et al., 2005;Hammett et al., 2006; Nassis et al., 2005). 
However, previous research only proves that physical exercise does not provide antiinflammatory effects, there is no research that says physical exercise exacerbate the presence of inflammation.

In the results of this study, physical exercise exacerbated the degree of inflammation, and was significantly different in the treatment group which treated with physical exercise compared to the control group without physical exercise. This can be due to several factors, which includes the inappropriate methode of physical exercise and the poorly conditioned environment that give more stress on mice, thus exacerbating the presence of inflammation.

The inappropriate physical exercise may give the same appearance with forced physical exercise. Voluntarily and forcefully physical exercise would affect the intestinal microbiota in mice, as proved by differences in both diversity and structure, and could affect many sites in the intestinal tract, such as the caecum and colon (Jacob et al., 2015), where changes in the microbiota could cause IBD (Allen et al., 2015). Dysbiosis can also cause the release of endotoxins and flagellins from Gram-negative bacteria that bind TLR-5 which will induce inflammation and damage from intestinal epithelium (Vijay-Kumar et al., 2010; Cani et al., 2008).

In another study conducted by Svensson et al. in 2016, it was found that forced physical exercise can induce stress responses by increasing anxiety and corticosterone levels, ischemia causes neuronal damage in the hippocampus and results in increase cytokines in brain tissue and blood flow (Svensson et al., 2016). Thusit can be concluded that forced physical exercise will increase stress, ischemia and neuronal damage indirectly, and can induce inflammation and epithelial damage directly. And in this study, stress was not only obtained from the inappropriate methode of physical exercise, the other two reasons are likely to cause mice stress, the first is the treatment group which given physical exercise and had to be moved three times a week, while the control group was almost never moved except when cage was being cleaned. Cage-switch induces stress on rats has been proven by Morimoto et al. study in 1993 (Morimoto et al., 1993), and the second in the treatment group mice, exercise was conducted during the day so that it interferes mice circadian rhythms, that resulted in mood disturbance (Vadnie et al., 2017).

Moreover, mice given physical exercise will need more water intake (Goodrick, 1978), therefore in this study, the treatment group will drink more water, and in this study induction of colon inflammation using $\lambda$-carrageenan diluted in drinking water, thus it can cause more severe inflammation in treatment group.

\section{CONCLUSION}

Physical exercise in mice induced $\lambda$ carrageenan resulted in worsening of inflammation both in terms of inflammatory cell infiltration and intestinal architecture.

\section{ACKNOWLEDGEMENTS}

We thank Dewi Ratna Sari, dr., M.Si (Histology Departement, University of Airlangga) who helped in taking samples pictures and Mr. Alfian (Biochemistry Departement, University of Airlangga) for technical support during the experiment. This study did not receive any external funding.

\section{REFERENCES}

Allen, J.M., Berg Miller, M.E., Pence, B.D., Whitlock, K., Nehra, V., Gaskins, H.R., White, B.A., Fryer, J.D., Woods, J.A. 2015. Voluntary and forced exercise differentially alters thegut microbiome in $\mathrm{C} 57 \mathrm{BL} / 6 \mathrm{~J}$ mice. J. App. Physiol., 118(8), 1059-1066.

Al-Suhail, A.A., Reid, P.E., Culling, C.F., Dunn, W.L., Clay, M.G. 1984. Studies of the degraded carrageenan-induced colitis of rabbits. I. Changes in the epithelial glycoprotein O-acylated sialic acids associated with ulceration. Histochem. J., 16(5), 543-53. 
Borthakur, A., Bhattacharyya, S., Dudeja, P.K., Tobacman J.K. 2007. Carrageenan induces interleukin-8 production through distinct Bcl10 pathway in normal human colonic epithelial cells. Am. J. Physiol. Gastrointest. Liver Physiol., 292(3), G829-38.

Buffie, C.G., Bucci V., Stein R.R., McKenney P.T., Ling, L., Gobourne A., No, D., Liu, H., Kinnebrew M., Viale, A., Litmann, E., Van den Brink M.R., Jeng, R.R., Taur, Y., Sander, C., Cross, J.R., Toussaint, N.C., Xavier, J.B., Pamer E.G. 2015. Precision microbiome reconstitution restores bile acid mediated resistance to Clostridium difficile. Nature, 517(7533), 205-8.

Cani, P.D., Bibiloni, R., Knauf, C., Waget, A., Neyrinck, A.M., Delzenne, N.M., Burcelin, R. 2008. Changes in gut microbiota control metabolic endotoxemia-induced inflammation in high-fat diet-induced obesity and diabetes in mice. Diabetes, 57(6), 1470-81.

Chong, A.S., Parish, C.R. 1985. Nonimmune lymphocyte-macrophage interaction. I. Quantification by an automated colorimetric assay. Cell Immunol., 92(2), 256-76.

Durigan, J.L.Q., Peviani, S.M., Russo, T.L., Silva, A.C.D., Vieira, R.P., Martins, M.A., Carvalho, C.R.F., Salvii, T.F. 2009. Effects of exercise training on atrophy gene expression in skeletal muscle of mice with chronic allergic lung. Braz. J. Med. Biol. Res., 42(4), 339-345.

Erben, U., Loddenkemper, C., Dorfel K., Spieckermann, S., Haller, D., Heimesaat, M.M., Zeitz, M., Siegmund, B., Kuhl, A.A. 2014. A guide to histomorphological evaluation of intestinal inflammation in mouse models. Int. J. Clin. Exp. Pathol., 157(8), 4557-76.
Flynn, M.G., McFarlin, B.K., Phillips, M.D., Stewart, L.K., Timmerman, K.L. 2003. Tolllike receptor 4 and CD14 mRNA expression are lower in resistive exercise-trained elderly women. J. Appl. Physiol., 95(5), 1833-42.

Ghia, J.E., Blennerhassett, P., KumarOndiveeran, H., Verdu, E.F., Collins, S.M. 2006. The vagus nerve: a tonic inhibitory influence associated with inflammatory bowel disease in a murine model. Gastroenterol., 131(4), 1120-30.

Gielen, S., Adam, V., Mobius-Winkler, S., Linke, A., Erbs, S., Yu, J., Kempf, W., Schuler, G., Hambrecht, R. 2003. Antiinflammatory effects of exercise training in the skeletal muscle of patients with chronic heart failure. J. Am. Coll. Cardiol., 42(5), 861-8.

Gleeson, M. 2007. Immune Function in sport and exercise. J. Appl. Physiol., 103(2), 6939.

Goodrick, C.L. 1978. Effect of voluntary wheel exercise on food intake, water intake, and body weight for C57BL/6J mice and mutations which differ in maximal body weight. Physiol. Behav., 21(3), 345-51.

Hammett, C.J., Prapavessis, H., Baldi, J.C., Varo, N., Schoenbeck, U., Ameratunga, R., French, J.K., White, H.D., Stewart R.A. 2006. Effects of exercise training on 5 inflammatory markers associated with cardiovascular risk. Am. Heart. J., 151(2), 367.e7-367.e16.

Kim, Y.J., Ju, J., Song, J.L., Yang, S., Park, K.Y. 2018. Anti-Colitic Effect of Purple Carrot on Dextran Sulfate Sodium (DSS)-Induced Colitis in C57BL/6J Mice. Prev. Nutr. Food Sci., 23(1), 77-83.

Ko, J.K., Anyeung, K.K. 2014. Inflammatory Bowel disease: etiology, pathogenesis and 
current therapy. Curr. Pharm., 20(7), 108296.

Kolios, G. 2016. Animal Models of Inflammatory Bowel Disease; how useful are they really. Curr. Opin. Gastroenterol., 32(4), 251-7.

Malik, F., Okhuysen, P., Alousi, A., Shpall, E., Shelburne, S., Petrosino, J., Rezvani, K., Ajami, N.J., Ghosh, N., Carlin L., Chemaly, R. 2015. Fecal Indole Correlates with Loss of Microbiome Diversity in Hematopoietic Stem Cell Transplant (HSCT) Recipients with and without Intestinal Graft versus Host Disease (iGVHD). Open Forum Infectious Disease at: IDWeek 2015., 2, 1-66.

Marcell, T.J., McAuley, K.A., Traustadottir, T., Reaven, P.D. 2005. Exercise training is not associated with improved levels of Creactive protein or adiponectin. Metabolism., 54(4), 533-41.

Martino, J.V., Van Liembergen, J., Cahili, L.E. 2017. The Role of Carrageenan and Carboxymethylcellulose in The Development of Intestinal Inflammation. Frointers in Pediatrics., 1(5), 96.

Morimoto, A., Nakamori, T., Morimoto K., Tan, T., Murakami, N. 1993. The central role of corticotrophin-releasing factor (CRF41) in psychological stress in rats. J. Physiol., 460, 221-229.

Narula, N., Fedorek, R.N. 2008. Exercise and Inflammatory bowel disease. Canad. J. Gastroenterol., 22(5), 497-504.

Nassis, G.P., Papantakou, K., Skenderi, K., Triandafillopoulou, M., Kavouras, S.A., Yannakoulia, M., Chrousos, G.P, Sidossis, L.S. 2005. Aerobic exercise training improves insulin sensitivity without changes in body weight, body fat, adiponectin, and inflammatory markers in overweight and obese girls. Metabolism., 54(11), 1472-9.
Nicklas, B.J., Ambrosius, W., Messier, S.P., Miller, G.D., Penninx, B.W., Loeser, R.F., Palla, S., Bleecker, E., Pahor, M. 2004. Dietinduced weight loss, exercise, and chronic inflammation in older, obese adults: a randomized controlled clinical trial. Am. J. Clin. Nutr., 79(4), 544-51.

Onderdonk, A.B., Hermos J.A., Barlett J.G. 1977. The role of the intestinal microflora in experimental colitis. Am. J. Clin. Nutr., 30(11), 1819-25.

Onderdonk, A.B., Hermos J.A., Dzink, J.L., Barlett J.G. 1978. Protective effect of metronidazole in experimental ulcerative colitis. Gastroenterol., 74(3), 521-6.

Packer, N., Hoffman-Goetz, L., Ward, G. 2010 Does physical activity affect quality of life, disease symptoms and immune measures in patients with inflammatory bowel disease? A systematic review. J. Sports Med. Phys. Fit., 50(1), 1-18.

Shang, Q., Sun, W., Shan, X., Jiang, H., Cai, C., Hao, J., Li, G., Yu, G. 2017. Carrageenaninduced colitis is associated with decreased population of anti-inflammatory bacterium, Akkermansia muciniphila, in the gut microbiota of C57BL/6J mice. Toxicol. Lett., 5(279), 87-95.

Svensson, M., Rosvall, P., Boza-Serrano., Andersson, E., Lexell, J., Deierborg, T. 2016. Forced treadmill exercise can induce stress and neuronal damaged in a mouse model of global cerebral ischemia. Neurobiol. Stress., 5, 8-18.

Vadnie, Chelsea, A., McClung, C.A. 2017. Circandian rhythm disturbance in mood disorders: Insight into the role of the suprachiasmatic nucleus. Neural plasticity., 2017, 1504507. 
Vijay-Kumar, M., Aitken, J.D., Carvslho, F.A., Cullender, T.C., Mwangi, S., Srinivasan, S., Sitaraman, S.V., Knight, R., Ley, R.E., Gewirtz, A.T. 2010. Metabolic syndrome and altered gut microbiota in mice lacking Toll-like receptor 5. Sci., 328(5975), 228-31.

Wehkamp, J., Gotz, M., Herrlinger, K., Steurer W., Stange, E.F. 2016. Inflammatory bowel disease', Dtsch Arztebl Int., 113(5), 72-82.

Wei, W., Feng, W., Xin, G., Tingting, N., Zhanghe, Z., Haimin, C., Xiaojun, Y. 2016. Enhanced effect of kappa-carrageenan on
TNBS-induced inflammation in mice. Int. Immunopharmacol., 39, 218-228.

Whittlem, C.G., Williams, A.D., Williams, C.S. 2010. Murine Colitis Modeling using Dextran Sulfate Sodium (DSS). J. Visualized Exp., 35, 1652.

Wu, W., Wang, F., Gao, X., Niu, T., Zhu X., Yan, X., Chen, H. 2016. Synrgistic effect of kappa-carrageenan on oxazoloneinducd inflammation in $\mathrm{BALB} / \mathrm{c}$ mice. BMC Gastroenterol., 25(16), 41. 